\title{
Correction to: Neonatal bacterial meningitis versus ventriculitis: a cohort-based overview of clinical characteristics, microbiology and imaging
}

\author{
Thomas Peros $^{1}$ (D) Joost van Schuppen ${ }^{2} \cdot$ Anneloes Bohte $^{3} \cdot$ Caspar Hodiamont $^{4} \cdot$ Eleonora Aronica $^{5} \cdot$ Timo R. de Haan $^{6}$ \\ Published online: 23 September 2020 \\ (C) Springer-Verlag GmbH Germany, part of Springer Nature 2020
}

\section{Correction to: European Journal of Pediatrics} https://doi.org/10.1007/s00431-020-03723-3

The last author of the original published version of the above article misses his middle name for correct identification. Timo de Haan has been presented correctly above as Timo R. de Haan.

Publisher's note Springer Nature remains neutral with regard to jurisdictional claims in published maps and institutional affiliations.

The online version of the original article can be found at https://doi.org/ $10.1007 / \mathrm{s} 00431-020-03723-3$

Thomas Peros

t.e.peros@amsterdamumc.nl

Joost van Schuppen

j.vanschuppen@amsterdamumc.nl

Anneloes Bohte

a.1.e.bohte@umcutrecht.nl

Caspar Hodiamont

c.j.hodiamont@amsterdamumc.nl

Eleonora Aronica

e.aronica@amsterdamumc.nl

Timo R. de Haan

t.r.dehaan@amsterdamumc.nl
1 Department of Pediatric Intensive Care, Amsterdam University Medical Centre, Amsterdam, Netherlands

2 Department of Radiology and Nuclear Medicine, Amsterdam University Medical Centre, Amsterdam, Netherlands

3 Department of Radiology and Nuclear Medicine, University Medical Centre Utrecht, Utrecht, Netherlands

4 Department of Microbiology, Amsterdam University Medical Centre, Amsterdam, Netherlands

5 Department of (Neuro) Pathology, Amsterdam University Medical Centre, Amsterdam, Netherlands

6 Department of Neonatal Intensive Care, Amsterdam University Medical Centre, Amsterdam, Netherlands 